\section{ANDRAGOGIKA VSAKDANJEGA ŽIVLJENJA - UČENJE OB DOŽIVLJANJU SMRTI}

\section{POVZETEK}

Smrt je rite de passage, s katerim se vsakdo sreča ob umiranju bližnjih, a še vedno razmeroma malo vemo, kako vpliva na posameznika. Besedilo poskuša odpreti razmišljanje o učenju v obdobju žalovanja in dodati drobec $k$ razumevanju učenja kot vseživljenjskega procesa.

$Z$ analizo življenjskih zgodb ugotavljamo, kako se posamezniki spreminjajo ob doživljanju smrti. Učenje poteka na telesni, duševni in duhovni ravni. Ljudje spreminjajo svoje odnose in vrednote. Pripovedovanje življenjske zgodbe ni le raziskovalna metoda, temveč je tudi odkrivanje samega sebe, kar omogoča spreminjanje samega sebe in samovzgojo.

Ključne besede: priložnostno učenje, biografsko in avtobiografsko učenje, vsakdanje življenje, žalovanje, smrt.

Z ahodna kultura se kaže kot kultura velikih možnosti. Izobraževanje je usmerjeno k temu, da iz življenja naredimo »zgodbo o uspehu«, pri čemer oznake uspeh, učinkovitost in kakovost izključujejo bolezen, smrt, trpljenje ter izgubo. Nasprotno od tega se v vsakdanjem življenju srečujemo z veliko izgubami. Izgubimo dragega človeka, ob bolezni lahko izgubimo del telesa. Umiranje ustvari poseben odmerek časa, v katerem se človek intenzivno spreminja. Žaluje in se premakne v drug mentalni prostor, kjer razvije nove interpretacije sebe in okolja, razvije novo plast identitete. Pri tem ni pomemben le razumski del učenja. Odkrivamo mnogo učnih zmožnosti, ki jih pogosto zanemarimo, če se osredotočimo le na razumsko plast učenja.
Raziskava, po kateri je nastalo besedilo, se je osredotočala na učenje ob dogodkih v vsakdanjem življenju. Tako imenovano priložnostno učenje (unintentional informal learning) težko odkrivamo, ker je brez »načrtov «, nima vnaprej pripravljenih vsebin ali prostorov, ljudje o njem ne razmišljajo posebej. Kaže se kot holističen proces, ki zajame celega človeka.

Večina raziskav se ukvarja $\mathrm{z}$ učenjem, ki je vsaj deloma strukturirano, zaobide pa učenje $\mathrm{v}$ vsakdanjem življenju. Na to so opozorile feministične raziskave (glej Hart, 1992) in deloma raziskave, ki so se ukvarjale $\mathrm{z}$ učenjem na delovnem mestu. Naša raziskava se je ukvarjala $z$ učenjem v družinskem okolju. Posebej so nas zanimala obdobja rojevanja, ločevanja, bolezni in umiranja. $\mathrm{V}$ besedilu predstavljamo del razi-
Dr. Nives Ličen, Maja Furlan, Simona Šinko 
skave, ki se je nanašal na učenje ob doživljanju smrti bližnjega.

Razprave o umiranju se nizajo v različnih vedah, religijah in umetnostih. Ponekod se osredotočijo

Priložnostno učenje nima vnaprej pripravljenih vsebin in je proces, ki zajame celega cloveka. na svojce umirajočih in umrlih, drugod na dogajanje v ritualih, na doživljanje umirajočega, poslavljanje duše, na socialno konstrukcijo umiranja in žalovanja, smrt opazujejo z biomedicinskega zornega kota, kot fiziološki proces. Slednji pogled na smrt prevladuje v zahodni kulturi. Naša raziskava odpira razmišljanje o učenju v obdobju žalovanja in sodi na področje andragogike vsakdanjega življenja. Naše izhodišče je, da v vsako novo obdobje vstopimo kot neizkušeni v novi kontekst. Tako tudi v obdobje srečevanja s smrtjo bližnjih. Učenje, ki se ob tem dogaja, lahko prepoznavamo s pomočjo različnih metod in teoretskih konceptov.

\section{BIOGRAFSKO IN AVTOBIOGRAFSKO UČENJE}

Pri opazovanju učenja v času žalovanja smo uporabljali koncept biografskega učenja, ki se povezuje z zamislimi izkušenjskega učenja, transformativnega učenja, učenja ob življenjskih prehodih in narativnega učenja, kot so jih opredeljevali različni avtorji, na primer Jarvis, Mezirow, Qualino, Tennant, Dirkx, Clark. Biografsko učenje upošteva različne ravni učenja, kot so razumska, čustvena, duhovna in somatska.

Za slednje ima podporo v nevroznanosti, ki ugotavlja gibkost možganov, »plastičnost « v ustvarjanju novih nevronskih povezav (glej Robertson, 1999). Koncept biografskega učenja poudarja, da se posameznik oblikuje/ vzgaja vse življenje (Alheit, 2002; Margiotta, 2006), posameznik soustvarja svoje znanje in svojo identiteto. To se izraziteje pokaže ob življenjskih prelomnicah, za kar uporabljamo
Biografsko učenje opazujemo kot učenje v življenju (Dominicé, 1992). Človek se uči od svojega okolja in sam s sabo. Vzgaja ga okolje in vzgaja sam sebe, kar Pineau (1983) poimenuje ecoformation in autoformation. Odrasli ni le naslovnik vzgoje, ki prihaja iz okolja, temveč sam (re)definira svoje življenje in kreira osebno biografijo.

tudi poimenovanje učenje ob prehodih (transitional learning).

Učenje poteka v bivanjskem loku, vpeto $\mathrm{v}$ socialno in kulturno okolje. Posamezniki so povezani v diade, skupine, razvijejo se podsistemi in medsebojno vplivanje med posamezniki ter skupinami. Učenje je odvisno od socialnega okolja. Posamezni dogodki, posebno taki, ki so v kulturi sprejeti kot izjemni in so pri posamezniku doživeti kot izjemni, kot je smrt, ponudijo možnost za raziskovanje odnosov do drugih in do samega sebe. Ob soočenju z izgubami se zdi, kot da se posameznik uči od samega sebe in za svoje najbolj intimne potrebe: čustvene, intelektualne in duhovne. Ne uči se več od sveta, ki ga obkroža. Ta tip učenja imenujemo avtobiografsko učenje (apprendimento autobiografico), s katerim posameznik svoja doživetja nadgradi z uporabo avtorefleksije oziroma introspekcije.

Sodobni človek pogosto »izpusti« dogodke, ki so povezani z bolečino in trpljenjem, ker mu okolje narekuje, da »mora « biti srečen in nenehno zadovoljen (Bruckner, 2004). Avtobiografsko učenje pomeni ozaveščanje vsega, tudi neprijetnega, progresivno poglabljanje, iskanje smisla in brušenje svoje identitete ob intrinzični problematiki bivanja na svetu. Poti, po katerih poteka, so različne. Qualino (2006) jih imenuje eksistencialno individualizirajoče. $S$ tem področjem učenja in vzgoje se ukvarja posebna poddisciplina - introspektivna pedagogika, ki razvija tudi avtobiografske metode (glej Demetrio, 2000).

Iz opisanega lahko sklenemo, da biografsko učenje ne pomeni le shranjevanja informacij 
$\mathrm{Z}$ avtobiografskim učenjem posameznik svoja doživetja nadgradi, pri tem pa uporablja introspekcijo, avtorefleksijo. Ta tip samovzgoje se povezuje $\mathrm{z}$ avtorefleksijo o temeljnih človekovih vrednotah. Korthgen (2005) jo imenuje »core reflection«. Razvije se $\mathrm{z}$ izkušnjami ali načrtno edukacijo. Za spreminjanje na ravni identitete je nujna posameznikova intimna pripravljenost (intima disponibilità, kot to imenuje Demetrio (2002), zmožnost opazovanja svojega doživljanja in prepoznavanja možnosti izbire.

in spretnosti ter reproduciranje zapomnjenega kot nečesa stalnega in stabilnega. Nasprotno: učenje - po tem modelu - pomeni nenehno mobiliziranje svojih virov in spreminjanje sebe. Učenje implicira začasnost naučenega, kar se v življenju kaže kot začasnost vlog, odnosov, interpretacij, pomenov, identitete. Poseben izziv za oblikovanje identitete $\mathrm{v}$ odraslosti je povezan $\mathrm{z}$ upadanjem, omejenostjo časa in umrljivostjo. Odraslost svojo dejavnost - drugače kot mladost - sooča z mejami, ki jih riše smrt. Ostro zavedanje o lastni umrljivosti se pokaže ob soočenju s smrtjo bližnjih, zato je to čas spraševanja o smiselnosti in poslanstvu $\mathrm{v}$ življenju.

Naslednja značilnost je poudarek na prepletu individualnega in socialnega, kulturnega in biološkega ter na kumulativnosti in medsebojnem vplivanju različnih vrst znanja in identitetnih plasti. Biografsko učenje razumemo kot proces autopoiesis (prim. Maturana, Varela, 1998), kot proces ustvarjanja svoje biografije ob bioloških danostih. Biografsko učenje je proces »autopoesis «, proces samoizgrajevanja $\mathrm{v}$ interakciji z okoljem.

Ljudje so refleksivni organizmi, svoje bivanje organizirajo v smiselne celote, iščejo identitetno koherentnost, celovitost. Oblikujejo življenjski svet in življenjsko perspektivo, ki je razmeroma stabilna $\mathrm{v}$ svojem dograjevanju. Koherentnost se najbolj izrazi s pomočjo kon- cepta narativnega učenja (Merriam, Caffarella, 2007: 207-216), ki prikazuje biografijo kot naracijo ali pripoved (primerjaj Ricoeur, 2001, 2004; Demetrio, 2002). Človekov razum ureja življenjska izkustva prvobitno in temeljno $\mathrm{v}$ pripovedih, zato je pripovedna misel zmožnejša zajeti resnico človeškega bivanja kot logična, abstraktna znanstvena misel. Iz tega je izhajala izbira metodologije raziskovanja.

\section{BIOGRAFSKO UČENJE JE OPREDELJENO S TREMI DIMENZIJAMI}

Implicitnost. Bistveni del biografskega učenja je impliciten, saj velik del učenja poteka na nezavedni ravni. Posledica tega dela učenja je tiho znanje (tacit knowledge). Nastaja biografska zakladnica znanja, ki se je ne zavedamo, dokler se v življenju ne znajdemo na križpotjih, kjer se odločamo o za nas pomembnih stvareh. $\mathrm{V}$ takih obdobjih lahko odkrijemo velike »zaplate« neozaveščenega znanja in ga dvignemo v sedanjost. Pri raziskovanju svojega učenja s pomočjo refleksivnih metod posameznik ugotovi, da se je v različnih okoliščinah naučil mnogo stvari, o katerih ni niti slutil, niti ni predvideval, da se jih bo naučil. Pojavile so se kot vzporedni rezultati. Nekatere spremembe, ki so posledice učenja, razume šele po tem, ko so dogodki že doživeti in se v času od njih odmakne. Primer takega učenja opazujemo pri starših, ki imajo otroke s posebnimi potrebami, ali pri popotnikih, kot v svojih raziskavah ugotavljata Krušič (2007) in Vukčevič (2008). Tiho znanje prenaša človek s seboj v času - iz prejšnjih okolij v sedanjost - in v prostoru - iz vzporednih okolij v druga okolja.

Socialnost. Biografsko učenje ne poteka le kot individualni proces. Odvisen je od komunikacije in interakcije $\mathrm{z}$ drugimi, zato opazujemo učenje $\mathrm{v}$ kulturnem kontekstu. Učenje je interaktivno in socialno strukturirano, a hkrati ima tudi »svojo lastno individualno logiko«, ki jo ustvarja specifična struktura posameznika. 
Koncept biografskega učenja ne reproducira zareze med osebnim in sociokulturnim učenjem, med individualnim in socialnim. Nasprotno: obe sferi poskuša združiti v strukturo učenja. V življenjskih zgodbah Narativno učenje je učenje skozi pripoved, skatero izražamo in hkrati ustvarjamo pomene, izražamo in hkrati ustvarjamo sebe. smo izbrali srečanje s smrtjo $\mathrm{v}$ družinskem krogu. To je dogodek, povezan z vsemi plastmi človekovega bivanja in $\mathrm{z}$ učenjem na različnih ravneh. Dotika se telesnosti (somatic learning), duhovnosti (spiritual learning), čustvenosti (emotional learning), povezan je z védenjem, prepričanji in navadami v kulturi. Ob prehodih se vzpostavljajo povezave med telesom in razumom ter pomeni v kulturnem okolju. Spraševali smo se, kakšne so značilnosti učenja v času žalovanja, katere ravni učenja lahko opazimo, kakšna je vloga naracije in socialnih mrež pri učenju ter kako se posameznik spreminja.

Življenjsko zgodbo posameznik pripoveduje nekomu drugemu (raziskovalki), hkrati posameznik z ubeseditvijo svoje življenjske zgodbe opazuje, kateri dejavniki so vplivali na oblikovanje njegove identitete, kako se sedanjost artikulira glede na preteklost. Zgodbe niso le izražanje, ekspresija pomenov in kompleksnosti življenja, temveč pomene tudi ustvarjajo. So konstitutivni del samoreprezentacije, kar nas pri opazovanju učenja vodi tudi v upoštevanje narativnega učenja med obdobjem raziskovalnih pogovorov. Prek pripovedovanih zgodb pripovedovalci ustvarjajo sebe. S konstrukcijo zgodbe rekonstruirajo sebstvo in so glavna oseba $\mathrm{v}$ procesu identizacije (Melucci, 1986). Ubesedena zgodba ni le element raziskovanja, temveč ima transformativno moč, inducira učenje. Pripovedovalke niso bile le sporočevalke. Pridobivanje informacij je bila le ena plast pogovora. Drugo plast je sestavljalo učenje. Med pripovedovanjem je potekal proces učenja. Zanimalo nas je, kako se bo ta proces odrazil $\mathrm{v}$ pripovedih, ali bodo ta proces opazile.

$\mathrm{Za}$ raziskovanje spreminjanja različni avtorji (Grbich, 2007; Gummeson, 2000; Greenwood, 1998) priporočajo uporabo kvalitativnih metod, zato smo izbrali pot tematske biografske pripovedi. S spoznanji iz pripovedi in analize literature želimo oblikovati poskusno teorijo o učenju v času žalovanja.
Model biografskega učenja poudarja večplastnost učenja. Vključuje zavestno in voljno učenje in tudi tiho, nezavedno učenje. To se dogaja $\mathrm{v}$ realnih prostorih bivanja. Poleg realnih prostorov človek goji tudi domišljijske prostore, ki niso del že doživetega. Učenje $\mathrm{v}$ teh prostorih poteka s pomočjo imaginacije in je za biografsko učenje pomemben, ker predstavlja rahljanje vezi s standardnimi pomeni. 


\section{METODA RAZISKOVANIA}

Raziskavo uvrščamo med narativne kvalitativne raziskave. Osredotoča se na to, kakšne pomene dajejo posamezniki svojim doživetjem. Pomeni se najbolje artikulirajo prek pripovedi (naracije), zato smo kot metodo izbrali življenjsko zgodbo in kot tehniko tematski biografski intervju. Kvalitativni pristopi so omogočili, da smo zbrali veliko deskriptivnih informacij. Nismo sledili vnaprej pripravljenim hipotezam, sledili smo pripovedi po načelu raziskave »ground up« (Merriam, 2002).

Zgodbe obravnavamo kot forme védenja. S pripovedovanjem svoje zgodbe daje posameznik pomen preteklim izkušnjam in raziskuje možnosti za bodoče delovanje, oblikuje pomene, smisel življenjskih dogodkov. Temu se med raziskovanjem nismo mogli izogniti. Subjektivnost pogovorov in vpliv raziskovalk na to predstavlja eno od omejitev pri oblikovanju teorije. Druga omejitev je majhen vzorec. Spoznanj tako ne moremo posploševati. Za to bi bile potrebne nadaljnje raziskave z večjim številom udeleženih.

\section{VZOREC, ZBIRANJE IN OBDELAVA PODATKOV}

Sogovornice so bile stare med 45 in 68 let. V skupini je sodelovalo sedem žensk. Vse so imele več kot srednješolsko izobrazbo, šest jih je bilo doma s podeželja, ena je bila iz večjega mesta. V prvem delu raziskave, to je v letu 2006, smo se dogovarjali s posameznimi možnimi pripovedovalci, ki so doživeli smrt v ožjem sorodstvu $\mathrm{v}$ preteklih treh letih. Teh je bilo 15, a niso bili vsi pripravljeni sodelovati. Izbrali smo zgodbe žensk, ki so se odločile, da bodo sodelovale v raziskavi. Zagotovili smo jim popolno anonimnost in možnost sodelovanja pri interpretaciji. Nato smo izvedli osrednji pogovor. Izkušnjo so strukturirale v zgodbo ob pomoči biografskega tematskega intervjuja. Zbiranje pripovedi je potekalo v letih 2006 in 2007. Opravili smo devet- najst »pogovorov«. S petimi smo se srečali trikrat, z dvema pa dvakrat. V prvem srečanju smo opisali potek, temu je sledil čas za razmislek ali so pripravljene svojo zgodbo o srečanju z umiranjem pripovedovati. Sledila je pripoved in nato ponovno srečanje ter preverjanje povedanega. Pri analizi pripovedi življenjskih zgodb smo najprej oblikovali kategorije, ki smo jih pri ponovni analizi skupaj s pripovedovalkami dopolnili in oblikovali tematske sklope: a) ravni učenja in sto-

S pripovedovanjem
dajemo pomen
preteklim izku-
śnjam in razisku-
jemo možnosti za
prihodnost.
pnje učenja, b) učenje žalovanja in pomen kulturnega konteksta, c) spreminjanje samega sebe. Življenjske zgodbe smo označili z zaporednimi številkami, ki jih uporabljamo tudi pri navajanju delov dobesednih pripovedi.

\section{REZULTATI}

Med zgodbe, ki vzgajajo, lahko uvrstimo tudi zgodbe, ki so polne bolečine ob doživljanju bolezni, umiranja in smrti. Čas, ki je svinčeno težak, postane paradoksno zlati čas spreminjanja, učenja. V nadaljevanju bomo nanizali nekaj ugotovitev, ki izhajajo iz analize pripovedi.

\section{a) Različne ravni učenja}

»Ko je umrla, sem imela videnje, da je švignil žarek $v$ nebo. Tisto noč nisem spala. Naslednje jutro sem bila utrujena. Potem se je začel v meni neki občutek, da ji je dobro. In tudi občutek, da sem svobodna. In ko sem se počutila svobodno, mi je bilo nerodno. Počutila sem se krivo, da se počutim svobodno. To sem večkrat pripovedovala sama sebi in ... predelovala«(ŽZ 1/2).

Tako je pripovedovala ena od informatork, ki je nato opisovala »urejanje« doživetja s po- 
močjo razmišljanja o doživetju in opazovanju same sebe. V nekaterih urah je morala zaposliti svoj um. Štela je kvadratke na prtu, da ni mislila. Potrebovala je samoto. Veliko je brala, še posebno literaturo o posmrtnem življenju. Če bi imela možnost, bi poiskala kakega medija. Kasneje je to tudi storila. Proces žalovanja lahko postane zelo dolg, ko se žalovanje poveže s krivdo. Taka kombinacija lahko vodi v različne patološke žalosti (Nemiah v Milivojević, 2000). Naša sogovornica jo je sama predelala. Pripovedovalka je interpretirala svoje doživljanje, spraševala se je o pomenih, kar ji je omogočilo, da je odkrila razne elemente svoje osebne zgodbe in načine učenja. Avtobiografsko učenje sloni na iskanju svoje resnice, kar se lahko zgodi Avtobiografsko učenje temelji na iskanju svoje resnice. se na telesni ravni kaže na različne načine. Nekateri občutijo glavobol, drugi doživljajo nespečnost, suha usta, bolečine v mišicah.

Pripovedovalka (ŽZ 3/2) prepozna lakoto, ki je najprej ni povezala $z$ žalovanjem. Ista pripovedovalka je doživljala v času žalovanja povečano spolno slo, kar jo je presenetilo in $\mathrm{v}$ njej vzbudilo zaprepadenost nad samo seboj.

Ko smo oblikovali zapis zgodbe, je odkrila M. Klein in njeno razpravo o objektnih odnosih. Ona sama je nato pojasnila svojo lakoto kot potrebo po tem, da nadomesti notranji objekt. In nato je povedala pri tretjem srečanju: »Sem mislila, da bo prešlo. Ko si bom razložila. OK, Melanie je dobro zapisala. Vse razumem. Lahko razložim. Ma, še vedno sem lačna« (ŽZ 3/3).

Izkaže se, da se učenje ne dogaja le na ravni védenja. Poznavanje teorij in interpretacij še ne omogoči, da bi spremenila svoje vedênje. Njeno učenje vključuje telo in v kasnejšem obdobju žalovanja je uporabljala masažo kot pot za »umirjanje same sebe« (̌̌Z 3/3). Ta se ji je zdela najboljša. Nekateri se začnejo ukvarjati z jogo, nekateri s fizičnim delom, kot je okopavanje vrta, razbijanje kamnov. Vse te strategije so lahko strategije učenja, lahko pa so tudi strategije potiskanja žalosti.

Blokiran proces žalovanja ali ne-učenje vodi v »inkapsulirano žalost« (ŽZ 5), ki vpliva na psihično delovanje človeka. Pokaže se lahko tako, da eksplodira v neki stresni situaciji. Vpliva tudi na somatski ravni. Upad imunske obrambe vodi $\mathrm{v}$ nastanek nekaterih obolenj, med njimi tudi malignih tumorjev (Milivojević, 2000: 609). Na tak način si lahko pojasnimo ljudske komentar-
Druga informatorka je občutila praznino, ki bi jo morala napolniti.

Občutila je telesne spremembe in telesne potrebe (lakoto). Psihoterapevti in raziskovalci emocij (Milivojević, 2000; Galati, 2002) opisujejo somatizirano emocijo. Posameznik ne prepozna telesnega odziva kot emocijo. Žalost
Psihoterapevti ugotavljajo, da ljudje uporabljajo tri strategije za utišanje žalosti. Občutek žalosti lahko posameznik utiša z neko prijetnostjo (hrana, spolnost, zabava, nakupi), ki pomeni beg pred žalostjo in spreminjanjem. Lahko ubere pot intenzivnega delovanja na drugih področjih (zamenja delo, dobi dodatno zaposlitev). Namen tega je, da preokupira svoj mentalni svet. Prva sogovornica je rekla, da je štela kvadratke na prtu. Ko gre za patološko strategijo, ljudje ne dovolijo sebi, da bi žalovali, in svoj občutek utopijo v hrani, delu, alkoholu, drogi. Milivojević (2000: 608) zapiše, da s tem le ustavijo proces žalovanja. Na nezavedni ravni ostajajo navezani na objekt in ne oblikujejo novih pomenov. 
je, da je nekdo »umrl od žalosti«. Žalovanje se v teh primerih ni povezovalo $\mathrm{z}$ učenjem kot spreminjanjem. Povezovalo se je predvsem z občutenjem, da ne more preživeti brez pokojnika.

\section{b) Sam se mora naučiti žalovati: izdelati vzor- ce vedenja}

V zahodni kulturi je smrt še vedno tabu. Ko se pogovarjamo o smrti, zakrivamo resnična čustva, kar se kaže tudi z uporabo besed, ki naj bi nadomestile glagol umreti. Ljudje zaspijo za zmeraj, odidejo med angele, nad zvezde, preselijo se v večnost, življenje se prekine, odidejo. Umiranje je ločeno od sveta, dogaja se v bolnišnicah, v sobah, ki so za to pripravljene. Obdaja ga občutek skrivnostnosti. Tudi medicinsko osebje se ob umiranju počuti neugodno. Priprava na pogreb in pogreb sta organizirana $v$ podjetjih, ki so za to najeta. Priprava mrtvega telesa za pokop je bila del družinskih ritualov, ki so bili prepojeni z načini žalovanja (Manca, 2005). $\mathrm{V}$ mnogih kulturah je smrt povezana z žalostjo, izkazovanje žalosti pa je povezano z ustaljenimi prepovedmi. Na primer, v Melaneziji vdove nekaj časa ne smejo prati, ker so po moževi smrti umazane. Pri nas se žalost kaže v prekrivanju grobov s cvetjem, prinašanjem sveč, čno obleko, neudeleževanjem zabavnega življenja. To obdobje je pri različnih ljudeh različno dolgo in različni ljudje uporabijo različen nabor navad. Nekateri se temu ognejo in najdejo svoje načine. Žalovanje ostane posamezniku, ki sam izumlja svoje vzorce žalovanja. $\mathrm{V}$ teh primerih lahko opazimo tako imenovano inovativno učenje.

Žalovanje poteka na različne načine, čustvene reakcije so različne, kar kažeta zgornji dve pripovedi. Prva pripovedovalka je doživela svobodo, a tudi občutek krivde, saj nosi v sebi zapoved, kakšni so primerni občutki ob smrti. »Ob smrti bližnjega se ne smeš počutiti svobodno, temveč žalostno« (ŽZ 1/3). Druga je doživela tako veliko pomanjkanje, da je morala notranjo praznino zapolniti snovno s hrano. Žalovanje poteka zelo različno, ker »žalovati ne pomeni, da se le sprijazniš z neko izgubo «, žalovanje »pomeni, da se spremeniš « (ŽZ 5/2). Nekateri ljudje ostanejo dolgo časa v svoji bolečini, spreminjanje/učenje lahko traja leta, a se nato vzpostavijo novi pomeni in novi načini življenja. Nekatera žalovanja obstanejo v depresivnih stanjih, pojavijo se bolezni, lahko tudi odvisnosti in želja po smrti, samomorilne misli.

»Bolečina me je razjedala. Bila sva skupaj 42 let. Začela sva iz nič. Sedaj so me vsi predmeti spominjaŽalovanje ne pomeni le sprijaznitev $z$ izgubo, ampak tudi osebno spremembo.

li nanj. Tam so ostali še 'čiki' v eni ribji konzervi.

Potem sem se srečala s sosedo, ki se je ločila po 20 letih zakona. Ona ni imela lepih spominov. Eno in drugo je zareza. Rana. Sem sama pri sebi mislila: jaz imam vsaj lepe spomine« (ŽZ 2/2).

Žalovanje je povezano z različnimi izgubami. Ženska žaluje ob ločitvi in smrti. Ženska po ločitvi mora podobno kot ženska, ki ovdovi, povleči svojo energijo ljubezni stran od moža (Milivojević; 2000: 601), vendar je žalovanje ene in druge prepleteno $\mathrm{z}$ različnimi spleti drugih občutenj. Prva verjetno, po zapisu psihoterapevtov izraža tudi bes, zamero, ǐšce napake (Milivojević, ibid.; Pasini, 2002). Pri obeh je žalovanje okolje za transformativno učenje, to je spreminjanje in prilagajanje novim okoliščinam, ki niso jasne. Vdova ne ve, kam sodi, in

Izgubljeni objekt ni le zunanji, temveč je tudi notranji. Vgrajen je v sistem predstav o svetu in sebi. Ko posameznik izgubi zunanji objekt, mora prilagoditi tudi intrapsihični svet, reorganizirati svoj sistem in ga prilagoditi zunanji realnosti. 
ne ve, kako naj se vede, da se bo »izkopala « iz žalosti (ŽZ 2/3). V generalizirani želji po atoniji posameznik nima vzorcev, reda in obreda. Badiou (2006) je v svojem delu Logiques des mondes razvil pojem »atonalnih svetov « (monde atone), to je svetov, ki jim manjka tonovski način. Ljudje nimajo točke, po kateri bi se odločali. To se dogaja tudi ob žalovanju, ko ni vidnih določil, kako naj poteka življenje $\mathrm{v}$ času po smrti bližnjega. V pripovedih smo zasledili: dnevno obiskovanje pokopališča, odhod na potovanje in v toplice, uporaba alkohola, pisanje romana, spanje $\mathrm{z}$ vnuki, izdelovanje podrobnega albuma, razstava fotografij po vseh prostorih stanovanja, izdelava oltarčka s podobo pokojnega v kuhinji in večkrat dnevno blagoslavljanje ter molitev kleče na stolu.

\section{c) Pomirjevala kot nadomestilo za rituale ža- lovanja? Pomen socialnih mrež in učenje $v$ odnosih}

»Kmalu po tem, ko mi je umrl mož, sem šla k svojemu zdravniku po svoja zdravila. In mi je rekel: Ali kaj potrebujete? Ne, zaenkrat še ne potrebujem. Če bi potrebovali še kaj drugega, pridite, vam bom napisal recept.

Kaj sem hotela, saj ne moreš ubežati žalosti. Moraš po tej poti naprej. Najbolj so mi pomagali prijatelji. Pojavili so se 'neznani' prijatelji. Moja sošolka iz osnovne šole, s katero nisva imeli stika že trideset let, neka sodelavka, ki sem ji pomagala pri delu. Pojavili so se ljudje, ki jih nisem pričakovala. In niso prišli tisti, ki sem jih pričakovala. Moj brat ni imel časa. Prišlo je tudi spoznanje, da znajo nekateri ljudje samo jemati. Niso kot Jobovi prijatelji, ki 'so sedeli z njim na tleh sedem dni in sedem noči in nihče mu ni rekel besede, ker so videli, da je njegova bolečina zelo velika'. V svoji žalosti sem bila zelo občutljiva. In to me je toliko bolj prizadelo. Bratova odsotnost je bila radioaktivno sevanje. Nisem izgubila le moža, izgubila sem tudi brata «(ŽZ 2/2).

Smrt je dogodek, ki prereže socialne strukture, zato je povezana z rituali, ki prisilijo živeče, da na novo vzpostavijo odnose in ponovno ovrednotijo odnosne povezave.

V zgoraj omenjeni družini so se redefinirale odnosne mreže tako, da so se prekinili odnosi v tisti socialni mreži, kjer je pripovedovalka pričakovala največjo socialno podporo. Razlogi za prekinitve odnosov so različni. Pogosto se odnosi prekinejo po smrti staršev zaradi razprtij ob dediščinah, ki so vzrok za vznik zavisti. Milivojević (2000) zapiše, da če v skupini prevlada čustvo zavisti, potem žalost enega ne izzove sočutja (sožalja) drugega, temveč izzove škodoželjnost. V teh primerih ne moremo pričakovati, da bo družinsko socialno omrežje delovalo kot podpora pri spreminjanju. Nasprotno: spreminjanje/učenje bo še dodatno zapletlo.

\section{c) Žalujoči v svoji žalosti prevzame lastnosti umrlega ali nove vrednote in interpretacije} v prvem pristanišču raztepla po svoje«. Nasprotje tega je, da se skupina, ki je doživela smrt svojega člana utrdi, okolje jo prepozna kot skupino. Morda se nekateri člani, ki so bili zunaj skupine, ob smrti povežejo s skupino. Obsmrtni rituali služijo skupini, da se re-definira, vzpostavljajo socialni red. Smrt ni le biološki dogodek, je tudi kulturni dogodek. Izražanje žalosti je sporočilo okolju, od katerega subjekt pričakuje neko reakcijo. Navadno je to solidarnost sorodnikov in prijateljev, ki se kaže v različnih oblikah pomoči. Vse to ne more vrniti mrtvega, a ima pomembno vlogo: izrazi naklonjenost (ljubezen) skupnosti, v kateri živi. 
»Po mamini smrti se mi je zgodilo nekaj nenavadnega. Prvič v življenju mi je nekdo rekel, da imam njeno dobrohotnost $v$ očeh. ( $V$ svoji telesni podobi nisem podobna mami, bolj svojim tetam po očetovi strani.) Čez nekaj tednov mi je gospa, ki je poznala mojo mamo, z menoj pa se je srečala prvič, dejala, da sem podobna mami« (ŽZ 3/2).

$» V$ meni se je zgodila sprememba ... Ne vem, ̌̌e je to posledica, da sem prevzela mamine lastnosti. Bolj se mi zdi, da je posledica tega, da se zodhodom nekoga, ki si ga imel rad in je bil velik del tvojega življenja, odpre nov uvid v vrednost v življenju. Bolj razumeš nekatere reči, ki jih prej nisi« (ŽZ 5/2).

\section{»Po mamini smrti nosim njen nakit«} (ŽZ 6/2).

Pripovedovalke povedo, da nosijo predmete pokojnih s seboj ali pa da sprejmejo nekatere vrednote, prepričanja, ki so jih pokojni gojili, pa jim one v času, ko so bili še živi, niso sledile. Nekatere menijo, da na tak način ohranjajo pokojnega ob sebi za nekaj časa.

Druga pa, da noče/ni hotela sprejeti odhoda matere, ker je ob njeni smrti občutila, da »definitivno« ni več otrok. Pripovedovalka je nosila mamin nakit približno pol leta. Druga pripoveduje, da je poleg svojega imena uporabljala še mamino, kar je trajalo kakšna dva meseca. Tedaj se ji je zdelo, da ne ve natančno, kdo je. Doživela je krizo svoje identitete. Ko se je spraševanje umirilo, je doživela mamino ime ob svojem kot smešno in grenko. Imela je občutek grotesknosti.

d) Prvi dnevi žalosti niso najhujši. Intenzivno spreminjanje se začne kasneje. Učenje ob žalovanju je počasno.

»Tedaj (na začetku) si poln napetosti in adrenalina, veliko je opravkov. Živiš, kot da se pripravljaš na potovanje ali slavje. Šele potem se začne trpljenje in spreminjanje referenčnega okvira, ko začutiš na dnu svojega drobovja, da ti je nekaj odvzeto, odrezan je del tebe. Kot da umre del mene« (ŽZ 5/2).

»V̌́asih se mi je zdelo kot, da človek v življenju ob vsaki izgubi malo umre in se potem malo rodi. Evo, to je spreminjanje. En del sebe izgubiš in zgradiš drugi del sebe. Samo, to ni kratkotrajno. To je 'u utrobi', nov del se rojeva v temi, počasi. Ni enostavno« (̌̌Z 5/3).

Pripovedovalka eksplicitno pove, da nastaja v njeni identiteti novi del, ki potrebuje vzgojo kot novi del. Ona se tega svojega novega dela zave, ker je prisluhnila sebi. Če v času ranljivosti tranzicije in žalovanja posameznik ne opazi novo nastajajočega, če ga spregleda, če živi tisoč drobnih opravil, ne da bi se spraševal o sebi, izgubi priložnost za refleksivno učenje.

\section{e) Radikalne spremembe, spremenjena orga- nizacija življenja}

Nekateri v žalovanju sprejmejo radikalne odločitve o preselitvi. Ingrid Trobish (1990) se je po moževi smrti preselila $v$ rodne ZDA. Ljudje poiščejo nov »kraj«, kjer se bodo počutili doma. Preselitev je znana tudi v drugih kulturah (prim. Telban, 2000). Požig koče in odhod v novo okolje je del vedenja po smrti otroka. V našem okolju je tako vedenje prisotno pri nekaterih ljudeh, vendar ni običajno. Ena od pripovedovalk si je kupila stanovanje v Ljubljani. Čeprav je že prej deset let živela v Ljubljani, je imela stanovanje le v najemu. Po mamini smrti se je odločila za nov dom. Dom. Nekaj je hotela »imeti« svojega. Njeno »biti« je zdaj dovoljevalo tudi »imeti $\ll$.

"Naučila sem se, da nihče nima neomejenega časa. In da si moram sedaj kupiti stanovanje» $(\check{Z} Z$ 1/2). 
Dobrodošle so praktične spremembe, drugačna organizacija časa, potovanja, ki se v pripovedih kažejo kot povezane $z$ »mesenim zavedanjem končnosti (ŽZ 5).

\section{f) Včasih se zgodijo stvari, da se smrt zdi »do- bra smrt«}

Posebne okoliščine nastopijo, ko umirajo otroci in za njimi žalujejo starši. Ko starši izgubijo otroke, velja to za najbolj tragično izgubo in tej sledi intenzivno žalovanje. Redko povezujejo smrt otrok s podobo »dobre smrti .

Ideologijo dobre smrti je vpeljal Ariès (1974, 1980) in se je nato razvijala z delom E. Kübler-Ross. Nekateri so skeptični do te ideologije, ker lahko vodi v ločevanje na dobre in slabe umirajoče in na vplivanje medicinskega osebja na vedenje umirajočih. Na tak način se lahko nevede vzpostavi socialni nadzor, ker bi bilo socialno sprejeto tako umiranje, kot je označeno z dobro smrtjo. V literaturi se kot »dobra smrt« pojavlja takšno umiranje, kjer je zagotovljeno nadzorovanje bolečine, zmožnost komunikacije in odločanja, priprava na smrt, občutek izpolnjenosti in priznanja drugih. Ljudje se predvsem bojijo umreti v bolečinah (Steinhauser in sodel., 2000). Vse te teme vsebujejo biomedicinske, psihološke, socialne in duhovne komponente.

Naš primer »dobre smrti« je drugačen. Ne vsebuje niti nadzora niti priprave. Globoko v pripovedi se kaže le izpolnjenost neke poti. V nekaterih primerih ljudje doživijo smrt kot »dobro smrt«, četudi je nasičena s tragičnostjo. Naša zgodba govori o otroku s posebnimi potrebami. Ni je doživela nobena od naših informatork. Ena izmed njih jo je povedala.

»Luka je bil avtist. Star je bil 13 let in tistih nekaj besed, ki jih je zmogel izgovoriti, je bilo povezanih z letenjem. Od prvih let je vedno rad opazoval ptice. Ure in ure jih je gledal, kako poletijo v nebo. Posnemal je letenje in velikokrat padel. Letel je z omar, mize ... Kot da ga nekaj žene $\mathrm{v}$ letenje, kot da je $\mathrm{v}$ njem zapisana neka druga dimenzija evolucije. Kot da je z letenjem odpiral edino svojo možno dimenzijo. Njegova družina ga je pazila, da se ne bi poškodoval. Spremljali so vsak njegov korak. A na koncu jim ni uspelo. Luka je naredil svoj zadnji polet z balkona - iz osmega nadstropja.

Njegov let je prinesel vsem neizmerno bolečino. Mama, oče, brat in sestra so naredili vse, da se ne bi poškodoval. Kako so trpeli vsa ta leta. A sprejeli so, da so naredili vse, kar so zmogli, potem se je zgodila usoda.

Taki ljudje, ki dajejo vse in brezpogojno sprejmejo nesreče, kar se zgodi, so junaki. Vendar so si tudi oni ustvarili razlago. Sinovo smrt so sprejeli z dostojanstvom, ker so menili, da bogovi ali kakor koli že imenujemo skrite sile, ki so naseljene v nas, so hoteli, da je hotel leteti in niso podprli naše želje, da bi bil normalen, podoben vsem drugim.

'Umrl je srečen', je rekla mama in nič več. Ni hotela več govoriti o tem« (̌̌Z 5/3).

Pri nekaterih hudih doživetjih ljudje onemijo. Včasih ne želijo svojega doživetja preliti v besede, ker se jim zdi, da bodo na tak način izgubili umrlega. Anica Mikuš Kos je v intervjuju (2008) pripovedovala o starših, ki so izgubili otroke v vojni in niso želeli pripovedovati o tem. Lawrence Langer (Williamson, 1998) piše o ljudeh, ki so doživeli holokavst, a o tem niso mogli govoriti, ker ni bilo besed, s katerimi bi sporočali grozo. Faza pripovedovanja je že faza spreminjanja. Ustavi jo lahko želja, da ohranja notranji objekt, ali pa pomanjkanje sredstev/besed, načinov izražanja.

\section{UGOTOVITVE O UČENJU V ČASU ŽALOVANJA}

Raziskave kažejo, da svojci umirajočih doživijo novo odgovornost, ki je povezana $\mathrm{z}$ naporom, strahom, slabim spanjem, pomanjkanjem časa, konflikti v družini, finančnimi omejitvami. Želijo si, da bi bilo za umirajočega dobro 
poskrbljeno (Andershed, 2006). Po smrti se v žalovanju začne novo obdobje in novo učenje. Naša skupina pripovedovalk je bila majhna, zato se nismo dotaknili vseh področij spreminjanja. $Z$ večjim številom ljudi bi verjetno odkrili še druga področja. A tudi ob omejenem številu lahko strnemo nekaj ugotovitev.

Učenje med žalovanjem se nanaša na naslednje spremembe: spreminja se sistem pomenov in vrednot, zgodi se oddaljevanje od izgubljenega objekta in prilagajanje novim pogojem. Gre za (pre)izpraševanje in dekonstrukcijo sistema pomenov ter ponovno rekonstrukcijo pri posamezniku. Spremenili se bodo zemljevidi pomenov, po katerem se posameznik orientira $\mathrm{v}$ zunanjem svetu. Procesi tega učenja ne potekajo načrtovano, pogosto tudi ne na zavestni ravni. Refleksija se včasih odvije, včasih pa ne. Transformativno učenje ni lahkotno, niti enostavno, saj se mora žalujoči naučiti živeti brez pokojnika (organizacija časa, denarja, stanovanja ...) in se razvezati od energije ponotranjenega objekta. Pokojniku mora »dovoliti, da odide«. Biografsko učenje kot oblikovanje pomenov, smisla in identitete se odvija na robu med individualnim in socialnim, zato ni linearen proces, niti ni sistematičen proces. Pomembno mesto imajo naključje, struktura možnosti ali omejitev, mreže že oblikovanih pomenov pri posamezniku in $\mathrm{v}$ kulturnem okolju, človekove zmožnosti, da okoliščine sprejme in se v njih uči. Če človek ne zmore soočenja $\mathrm{z}$ izgubo in učenja, lahko to vodi $\mathrm{v}$ omamo in bolezen. Človek ima $\mathrm{v}$ žalovanju vsaj dve možnosti. Ena je učenje, to je spreminjanje mentalnih shem, navad, delovanja v okolju, in poteka $\mathrm{v}$ različnih modelih. Druga pot je razvoj depresivnega občutenja, patološkega žalovanja, ki vodi v psihosomatska obolenja.

\section{Faza pripovedova- nja je že faza spre- minjanja.}

\section{RETROSPEKTIVNA REFLEKSIJA IN UČENJE MED PRIPOVEDOVANJEM}

Pri tretjem pogovoru, med skupno interpretacijo pripovedi, so ugotavljale svoje učenje med pripovedovanjem zgodbe. Učenje med pripovedovanjem se je pokazalo kot nastajanje novih povezav med pomeni. Nastajale so nove interpretacije kulturnih vzorcev in z njimi povezave med individualnim in socio-kulturnim. Te segmente bi lahko pojasnili s konceptom narativnega učenja. Pripovedovalke so poudarile pomen ubeseditve in skupne refleksije ter oblikovanje individualiziranih odgovorov $\mathrm{v}$ drugi in tretji fazi pogovora. $\mathrm{V}$ vsakdanjih pogovorih nihče ne pričakuje individualiziranih odgovorov, pri raziskovalnem intervjuju pa je drugače. Počutile so se motivirane, da povedo, »kaj prav zares mislijo« (ŽZ 7/3). Pripovedovalke je spodbudilo to, da koga zanimajo njihovi občutki, da je kdo pripravljen poslušati

Učenje opazimo kot transformacijo posameznika. Temu procesu je lahko okolje $\mathrm{v}$ oporo $\mathrm{s}$ skrbnostjo, presojo, analizo dogajanja, ki je pri vsakem človeku drugačno, in z informacijami, ki jih potrebuje. Učenje poteka kot informativni proces (iskanje znanja s pomočjo knjig, interneta, svetovalcev) in transformativni proces (spreminjanje posameznika). Pojavlja se inovativno učenje, kjer se oblikujejo svojske poti žalovanja in vpeljejo radikalne spremembe $\mathrm{v}$ življenje. Učenje poteka nezavedno (sprejemanje kulturnih vzorcev) in na zavestno konstruktivni ravni. Učenje se odvija $\mathrm{v}$ dinamiki med življenjem pripovedovalk in spreminjajočim se kontekstom. Ta se je ob smrti tako spremenil, da se je pojavila nuja reorganiziranja življenja. Iz pripovedi lahko ugotovimo, da poteka učenje na različnih ravneh (racionalno, somatsko, emocionalno, duhovno). Za njihovo učenje so pomembne socialne mreže. Poudarjajo, da je učenje $\mathrm{v}$ energiji žalovanja počasno. 
njihova razmišljanja, ki se spreminjajo. Ker je med drugim in tretjim pogovorom potekel kak teden, deset dni, so pri tretjem pogovoru povedale, da opazujejo nekatere dogodke ob smrti drugače, da svoje okolje drugače presojajo. Po njihovem mnenju se to ne bi zgodilo (ŽZ $1,4,6)$, če ne bi imele »razsvetljenega poslušalca« ( $\check{Z} Z$ 6/3). V pogovorih so vzpostavile refleksijo in začele oblikovati svoje posplošitve. Spreminjale so svoje vedenje, prepričanja. Pokazalo se je, da se je refleksija razvila ob drugem človeku, s katerim so se ozrle na svoja doživetja. Podobne rezultate o pomenu nekoga, ki prisluhne, pokažejo raziskave na področju izkušenjskega učenja med kolegi na delovnem mestu (Truijen, Woerkom 2008). V preteklosti so ljudje žalovali ob pokojniku več dni in so imeli priložnost biti poslušani, bila je ustaljena možnost, da so pripovedovali. V sodobnih načinih poslavljanja od pokojnikov je malo možnosti za pripovedovanje, zato je tudi manj možnosti za retrospektivno refleksijo.

\section{RAZLIČNE STRATEGIJE UČENJA, KOT SE IZRAZIJO NA RAVNI VEDENIA - POSKUSNA TEORIJA}

$\mathrm{Na}$ osnovi pogovorov in analize literature smo oblikovali poskusno teorijo o učenju v času Žalovanja. Učenje smo razmestili v štiri strategije učenja.

Učenje ob doživljanju smrti se na prvi pogled zdi povezano predvsem $\mathrm{z}$ vdanostjo in prilagajanjem dejstvom, vendar je ob tem mogoče opaziti več odtenkov, morda celo strategij. Naše pripovedovalke so pri učenju uporabljale tri strategije, četrto pa lahko zaznamo v pripovedih $\mathrm{v}$ literaturi. Vse tri strategije so umeščene med socialnim in individualnim. Učenje je potekalo pod vplivom socialnega okolja in individualnega življenja, nabora znanja, prepričanj, vrednot ter oblikovanih osebnostnih lastnosti.

Prva strategija je adaptacija, prilagajanje, ker so okoliščine doživete kot nespremenljive.
Prilagodile so se izgubi in tudi socialnim pričakovanjem glede vedenja (vdovstvo). Učenje poteka predvsem v vdanosti. Nekatere so »preveč« vdane, tako da je njihova možna pot v somatizacijo žalosti.

Druga strategija pomeni identitetno rast. Ta se zgodi pri tistih pripovedovalkah, ki začutijo del razmer kot nespremenljiv (smrt). Poleg tega pa tudi del, ki ga lahko spreminjajo, na katerega lahko vplivajo. Ta del najdejo v sebi. Posameznica je poskrbela zase $\mathrm{v}$ soočenju $\mathrm{z}$ izgubo tako, da je začela spreminjati sebe, svoje razmere je kritično presojala in izbirala druge načine interpretacije ali vedenja/delovanja. Zave se, da lahko oblikuje del sebe, in to začne gojiti.

Tretja strategija predstavlja razvoj popolnoma drugačnega sloga življenja. Razmere, v katerih se znajde po smrti, so zanjo utesnjujoče, zato odide v nov kraj, novo jezikovno in kulturno okolje (preseli se iz Slovenije v Kanado).

Četrta strategija se v naši raziskavi ni pokazala neposredno. Nobena od pripovedovalk je ni razvila. Lahko bi jo dodali, ker jo odkrijemo $\mathrm{z}$ analizo pripovedi v literaturi. Nekateri ljudje izberejo pot spreminjanja okolja. Postanejo dejavni, na primer v sklopu hospica. Nekatere matere po smrti svojih otrok napišejo knjigo, da bi spodbujale razmišljanje o smrti otrok (Zečević, 2003), nekatere spodbudijo akcijo za pripravo pokopališča za mrtvorojene otroke in podobno.

\section{ZAKLJUČEK}

Doživetje smrti nosi v sebi energijo za spreminjanje identitete in spreminjanje vrednot. Ko se posameznik sreča $\mathrm{z}$ minljivostjo, postane življenje pomembno. Včasih so boleči dogodki, ki jim dovolimo, da nas preidejo, tisti trenutek, ko se srečamo sami s sabo in s spraševanjem o smislu življenja. Sodobni človek je razpršen med mnogimi možnostmi in trdna referenčna točka postane le še smrt, minljivost. 
Vsako žalovanje je tako osebno kot tudi kulturno dejanje. Ljudje žalujejo skladno s kulturnimi pričakovanji. Če je učenje v prvi strategiji podreditev tem pričakovanjem, je v drugi in tretji spreminjanje sebe, $\mathrm{v}$ četrti strategiji pa spreminjanje okolja.

Morda je to možnost, da začne verjeti vase in v zmožnost, da se spreminja. Po preobrazbi posameznik ustvari nove identitetne plasti, nova prepričanja (drugo strategijo), če ne dovoli žalosti, da ga potisne v stagnacijo (prva strategija).

»Gledala sem metulja, ki se je približeval moji skodelici kave. Prešinilo me je: če je bil on črv in se je spremenil, se lahko tudi jaz spremenim. Morda nam trpljenje govori o tem, da je treba poleteti stran « (ŽZ 6). Trpljenje omogoča, da se oddaljimo od nekih (za)misli, ki so se morda zdele prave. Šele potem spoznaš, da niso bile prave (ŽZ 5).

Prepričanja so globoko zakoreninjena in spremembe se ne zgodijo hitro. Ljudje razmišljajo v kontekstu specifičnih kulturnih vrednot, zapovedi, kako naj občutijo smrt bližnjega. S sogovornikom lahko razklenejo ustaljene mentalne sheme ali spremenijo načine, kako jih uporabljajo. Lahko spremenijo svoj življenjski slog (tretja strategija) ali začno dejavno posegati v okolje (četrta strategija).

$\mathrm{V}$ prehajanju različnih faz, od šoka do jeze in depresije, človek z žalovanjem predeluje sam sebe. Trpljenje samo po sebi v posamezniku ne povzroči sprememb. S trpljenjem se družijo tudi žalost, potrpežljivost, razumevanje, odprtost za spreminjanje in posameznikovo dojemanje dogodkov in svojih zmožnosti. Tako človek sklene mir z odhajanjem in prihajanjem novega. Preide faze od objokovanja tistega, kar je bilo zamujeno (»Nisem je vprašala, kako je ona skuhala ječmenko (ŽZ 3), nisva šli v Moskvo (ŽZ 6), do faze, ko dela, kar bi pokojnik rad delal (»Urejam vrt, stanovanje« (ŽZ 5). Nato pokojniku malo očita, kaj je naredil narobe (»ko se vsaj ne bi toliko vtikala v druge in jim hotela pomagati « (̌̌Z 5), sledi občudovanje umrlega (»o mrtvih vse dobro«). Potem sprejme, da ga ni več, ne trudi se ohranjati preteklosti, zave se nedokončanosti in začasnosti ter (večinoma) zmore prehod, sprejetje, da je v življenju marsikaj zaznamovano $\mathrm{z}$ nedokončanostjo, nedoločljivostjo. Blagostanja v življenju ne dosegamo z zanikanjem žalosti in bolečine, temveč $\mathrm{z}$ oblikovanjem smiselnosti, kar je povezano s samovzgojo. Žalovanje ni povezano le z življenjem pokojnika, povezano je predvsem z biografijo posameznika, ki ostaja, se ob tem uči, razvija svoje »identitetne projekte« in sposobnosti za nova povezovanja, spreminjanje vedenja ter oblikovanje novih interpretacij ob temeljnem zavedanju končnosti.

\section{LITERATURA}

Alheit, P., Dausien, B. (2002). »Lifelonglearning and Biographicity«. V Bron, A., Schemmann, M. (ur.) Social Science Theories in Adult Education Research. Munster: LIT, str. 211-242.

Andershed, B. (2006). Relatives in end-of-life-care. Part 1: a systematic review of the literature the five last years, January 1999-February 2004. Journal of Clinical Nursing, 15, str. 1158-1169.

Ariès, P. (1974, 1980). The Hour of our Death. New York: Knopf.

Badiou, A. (2007). Being and event. London, New York: Continuum.

Bruckner, P. (2004). Nenehna vzhičenost. Ljubljana: Študentska založba.

Castiglioni, M. (2002). La ricerca in educazione degli adulti. L'approccio autobiografico. Milano: Unicopli. Chappell, C. et al. (2003). Reconstructing the Lifelong Learner. Pedagogy and identity in individual, organisational and social change. London, New York: Routledge.

Conti, M., Fabbri, M., Manuzzi, P. (2006). Non di solo cervello. Educare alle connessioni mente-corpo-significati-contesti. Milano: Raffaello Cortina Editore. Demetrio, D. (ur.) (2002). »Il metodo autobiografico«. V: Demetrio, D., Alberici, A. (ur.). Istituzioni di 
Educazione degli adulti. 1. Il metodo autobiografico. Milano: Guerini scientifica.

Demetrio, D. (2000). L'educazione interiore. Introduzione alla pedagogia introspettiva. Firenze: La Nuova Italia.

Demetrio, D. (2003). Autoanalisi per non pazienti. Milano: Cortina.

Dominicé, P. (1992). L'histoire de la vie comme processus de formation. Paris: L'Harmattan.

Galati, D. (2002). Prospettive sulle emozioni e teorie swl soggetto. Torino: Bollati Boringhieri.

Goodley, D., Lawthom, R., Clough, P., Moore, M. (2004). Researching Life Stories.

Method, Theory and analyses in a biographical age. New York, London: Routledge.

Grbich, C. (2007). Qualitative data analysis. London: Sage.

Gummesson, E. (2000). Qualitative Methods in Management Research. Thousand Oaks: Sage.

Hart, U.M. (1992). Working and Educating for Life. Feminist and International Perspectives on Adult Education. London: Routledge.

Korthagen, F., Vasalos, A. (2008). Levels in reflection: Towards Tailor-made Supervision of teaching practice. www.ivlos.uu.nl/deorganisatie/wiewatwaar/ medewerkers/korthagen (20. oktobra 2008).

Krušič, A. (2007). Izobraževanje staršev otrok s cerebralno paralizo. Diplomsko delo. Ljubljana: Filozofska fakulteta.

Manca, M.C. (2005). Le cerimonie funebri come riti di passaggio. Milano: FrancoAngeli.

Margiotta, U. (2006). Pensare la formazione. Milano: B. Mondadori.

Melucci, A. (1996). The playing self. Cambridge: Cambridge university press.

Merriam, S.B. and ass. (2002). Qualitative Research in Practice. San Francisco: Jossey Bass.
Merriam, S. B., Caffarella, R. S., Baumgartner, L.M. (2007). Learning in adulthood. San Francisco: John Wiley\&Sons.

Milivojević, Z. (2000). Emocije. Novi Sad: Prometej. Morgan-Klein, B., Osborne, M. (2007). The Concepts and Practices of Lifelong Learning. London, New York: Routledge.

Pasini, W. (2002). I nuovi comportamenti amorosi. Milano: Mondadori.

Pineau, G., Pineau, M-M. (1983). Produire sa vie: autoformation et autobiographie. Montreal: Saint Martin.

Ricoeur, P. (2004). Ricordare, dimenticare, perdonare. Bologna: Il Mulino.

Robertson, I.H. (1999). Il cervello plastico. Milano: Rizzoli.

Steinhauser, K.E. et al. (2000). »In Search of a Good death: Observations of Patients, Families, and Providers«. Annals of Internal Medicine. Vol. 132, str. 825-832.

Telban, B. (2000). Andaypa: eseji o smrti v novogvinejski skupnosti. Maribor: Obzorja.

Trobish, I. (1990). Ko ostaneš sam. Celje: Mohorjeva družba.

Vukčevič, R. (2008). Učenje skozi potovanje. Diplomsko delo. Ljubljana: Filozofska fakulteta.

West, L., Alheit, P., Andersen, A.S., Merrill, B. (2007). Using Biographical and Life History Approaches in the Study of Adult and Lifelong Learning: European Perspectives. Frankfurt am Main: PeterLang.

Williamson, B. (1998). Lifeworlds and learning. Essays in the Theory, Philosophy and Practice of Lifelong Learning. Leicester: NIACE.

Zečević, B. e tal. (2003). Prazna zibka, strto srce: staršem, ki so izgubili otroka med nosečnostjo ali kmalu po porodu. Krško: Društvo Solzice 